\title{
Allergic diseases - current state of knowledge
}

\author{
Wioletta Żukiewicz-Sobczak ${ }^{1,2}$, Ewelina Krasowska', Jacek Zwoliński ${ }^{1}$, Paweł Sobczak ${ }^{3}$, Jolanta Chmielewska-Badora', \\ Paula Wróblewska', Jacek Piątek ${ }^{1}$, Andrzej Wojtyła ${ }^{2}$
}

\author{
1Department of Allergology and Environmental Hazards, Institute of Rural Health, Lublin, Poland \\ Head: Dr Wioletta Żukiewicz-Sobczak \\ 2Department of Health Promotion, Food and Nutrition, Institute of Rural Health, Lublin, Poland \\ Head: Andrzej Wojtyła MD, PhD \\ ${ }^{3}$ Department of Food Engineering and Machinery, University of Life Sciences, Lublin, Poland \\ Head: Prof. Kazimierz Zawiślak PhD
}

Postep Derm Alergol 2012; XXIX, 6: 451-455

DOI: 10.5114/pdia.2012.32393

\begin{abstract}
Allergic diseases are very common in developed countries, particularly among children, adolescents and young adults. Currently, allergies are being considered as an epidemic of the $21^{\text {st }}$ century. According to the Polish Society of Allergology, the percentage of adults suffering from asthma in our country is $5.4 \%$, and in children $10 \%$. The authors describe current knowledge regarding the pathomechanism, incidence, epidemiology and diagnostics of the most common significant allergic diseases, including allergic rhinitis, asthma, allergic conjunctivitis, atopic dermatitis and urticaria. One of the most common allergic diseases is allergic rhinitis, which is the result of an allergic inflammation of the nasal mucosa mediated by immunoglobulin E. Asthma is a lifelong chronic inflammatory disorder of the airways associated with a variety of structural changes occurring in children and adults of all ages. This disease is characterized by bronchial hyperreactivity and obstruction which often disappear either spontaneously or with treatment. Atopic dermatitis is a chronic and relapsing inflammatory skin disease with a varying clinical spectrum, and may often play the role of the first stage of the atopic march. Urticaria is a heterogeneous group of diseases, characterized by the presence of wheals and/or angioedema. The mainstay of allergy diagnosis is in vivo and in vitro testing. In vivo testing includes skin prick tests, prick-by-prick tests, atopy patch tests and also skin application skin test. In vitro testing includes measurement of serum total and antigen-specific IgE using various methods. During the last years, also component-resolved diagnostics have gained growing importance as a useful tool in clinical investigation of IgE-mediated allergies.
\end{abstract}

Key words: allergy, allergic diseases, epidemic.

\section{Introduction}

The term "allergy" (Greek - allos ergon) was introduced in 1906, by Clemens von Pirquet, an Austrian pediatrician and professor of the universities of Wroclaw and Vienna. Originally, the term referred to the altered organism response to an antigen which has been introduced repeatedly. With time, it was used as a synonym for allergic reactions of the system [1]. Allergy may be elicited by virtually any substance, both naturally derived and man-made. Each particle small enough to move through the air can then enter the respiratory tract and be introduced to the immunological system (e.g., dust, mold spores and pollen) [2-4].

Allergic diseases are very common in developed countries, particularly among children, adolescents and young adults. Currently, allergies are being considered as an epidemic of the $21^{\text {st }}$ century. According to data from the Pol- ish Central Statistical Office, among chronic diseases, asthma and allergies belong to the most common causes of morbidity in patients up to 30 years of age. Furthermore, the direct costs associated with medical visits and purchase of medicines and also indirect costs resulting from a lower work productivity are increasing [5]. The increasing prevalence of asthma, allergic skin diseases and allergic rhinitis is comparable with the progress of the AIDS epidemic. In the 1960s the prevalence of 'classical' allergic disease - pollinosis - in Europe, the United States and Japan was estimated to be $0.5 \%$ to $2 \%$ of the total population. Today the situation has changed dramatically in some parts of the world and the percentage reaches $30 \%$ of people. It is estimated that the number of chronically allergic patients in Europe includes more than 10\% of the population and $30 \%$ of European Caucasians experience at least one

Address for correspondence: Wioletta A. Żukiewicz-Sobczak PhD, Institute of Rural Heath, 2 Jaczewskiego St, 20-090 Lublin, Poland, phone: +48 6981437 43, e-mail: wiola.zukiewiczsobczak@gmail.com 
episode of allergy during life. According to the Polish Society of Allergology the percentage of adults suffering from asthma in our country is $5.4 \%$, and in children $10 \%$. This figure is several times higher than the data from the early 1970s [6]. The area of Central and Eastern Europe has a particularly high rate of growth in the incidence of allergic diseases, which may be related to the socio-political system that resulted in the development of industrialization, "chemicalization" of life and improved hygiene [7, 8].

\section{The most common allergic diseases}

Allergens are proteins or glycoproteins with a molecular weight of 5-50 kDa that initiate and are responsible for the manifestation of the IgE-mediated type I allergic reaction. The lower value is important for immunogenicity, while the upper value determines penetration through the mucosa. There are no physicochemical differences between allergens and other antigens that may explain the ability of the former to induce IgE responses. Thus, there is no common characteristic of the amino acid sequences of different allergens. The differences in the immune response in examined patients depend not only on the variety of allergens, but also on the different epitopes (antigenic determinants) of the same allergen molecules. This variation in response is genetically determined. An individual patient's sensitivity to an allergen depends on the major histocompatibility complex class II (MHC), which controls the processing and presentation of antigen [9-11].

One of the most common allergic diseases is allergic rhinitis (AR), which is the result of allergic inflammation of the nasal mucosa mediated by lgE (immunoglobulin E). Currently, the disease occurs in 10-30\% of the population, and the incidence of AR has increased around the world. The disease is considered as a risk factor in the development of asthma [12-15]. Allergic conjunctivitis is an increasingly common allergic disease with the same clinical significance as allergic asthma and allergic rhinitis. This term includes various distinct disease entities, ranging from benign, but troublesome form of conjunctivitis associated with lgE hypersensitivity to airborne allergens to disorders with severe allergic inflammation and involvement of the conjunctivae and cornea. The latter are more difficult to diagnose and treat and can lead to permanent eye damage and even blindness. Inflammation of the nasal mucosa and paranasal sinuses is one of the most common and the most cost-generating diseases occurring in many forms [15]. Asthma is a lifelong chronic inflammatory disorder of the airways associated with a variety of structural changes occurring in children and adults of all ages. This disease is characterized by bronchial hyperreactivity and obstruction which often disappear either spontaneously or with treatment. Asthma is a serious public health problem throughout the world, especially in countries with low and middle income, because of the very rare diagnosis and inappropriate treatment [15-20]. Atopy is a genetic pre- disposition to the development of hypersensitivity to common airborne allergens with IgE. It is the most frequently detected predisposing factor for the development of asthma, especially in children. Atopic dermatitis is a chronic and relapsing inflammatory skin disease with a varying clinical spectrum, and may often play the role of the first stage of the atopic march. In spite of variable research methods, the pathomechanism of the dermatosis has not yet been fully elucidated. An important role in the pathophysiology of atopic dermatitis is associated with structural and functional disturbances of the epidermal barrier, as well as disturbances of innate and adaptive immunity, inflammation, infectious factors, and the surrounding environment (airborne allergens, food allergens). Additionally, lgE antibodies directed against autoantigens may be the cause of the immediate reaction, but also may stimulate dendritic cells [15, 21-23].

According to the World Allergy Organization (WAO), anaphylaxis has been defined as a severe, life-threatening generalized or systemic hypersensitivity reaction. It is suggested that the term allergic anaphylaxis should be used to describe immunological reactions involving IgE, IgG or immune complexes. An IgE-mediated allergic anaphylaxis is associated with systemic release of mediators by mast cells and basophils. If, on the other hand, non-immunological mechanisms are involved, WAO suggests that the term 'non-allergic anaphylaxis' be used. It is estimated that about 220-250 million people worldwide suffer from food allergies [11].

Urticaria is a heterogeneous group of diseases, characterized by the presence of wheals and/or angioedema. Urticaria is a common condition, and the overall lifetime incidence rate is more than $20 \%$. Chronic urticaria is characterized by recurring episodes of spontaneous transient wheals and pruritus, with or without angioedema, which can persist for $\geq 6$ weeks. It has to be emphasized that chronic urticaria impairs the quality of life, and there is still a need for seeking new effective treatment methods. The pathogenesis of urticarias is variable, and some types of urticarias are associated with allergic reactions, mostly IgE-mediated (type I hypersensitivity reactions) and mediated by immune complexes (type III hypersensitivity reactions).

Drug adverse reactions occur in nearly $1 / 10$ of the world population and in nearly $20 \%$ of all hospitalized patients. Over $10 \%$ of adverse drug reactions are unpredictable hypersensitivity reactions. Clinical forms of drug hypersensitivity reactions are heterogeneous, but urticaria and maculopapular eruptions are the most frequent manifestations. The tools allowing a definite diagnosis of drug hypersensitivity include a thorough clinical history, standardized skin tests and drug provocation testing.

Allergy to insect venoms may be associated with severe local reaction or systemic allergic reaction [24]. Mild systemic reactions may be limited only to the skin as a sudden facial erythema, urticaria and angioedema, while severe 
reactions can cause system bronchospasm, laryngeal edema, and hypotension. Insects, foods and medications are the three most common triggers for anaphylaxis. All of the mentioned triggers are sources of considerable morbidity and mortality, but of the 3 , only insect allergy is treatable through means other than trigger avoidance. It is suggested that at least 40 deaths per year are attributed to insect stings and healthcare workers should be aware how to establish proper diagnosis as well as how to conduct long-term treatment of this potentially lifethreatening allergy. The diagnosis of insect allergy relies on a history of a systemic allergic reaction with appropriate testing for venom-specific IgE. Insect venom specific immunotherapy should be considered as disease-modifying therapy that may provide effective protection against future adverse reactions to the affected allergic patient.

Allergic occupational diseases are an important health problem because of their high prevalence and socio-economic burden. To a large extent, they are under-recognized by physicians and patients and in occupational medicine. In industrialized countries, the incidence of allergic diseases has been increasing for more than 50 years, while the incidence of allergy to at least one of the allergens commonly found among children of school age is currently 40-50\% [15, 25-27].

\section{Predisposition to the development of allergic diseases}

Among the predisposition of individuals to the development of allergic diseases genetic factors play the main role. The importance of genetic factors can be shown using an example of the compatibility of cases of atopic dermatitis, which was found in $86 \%$ of monozygotic twins and only in $21 \%$ of dizygotic twins. Inheritance is likely to be multigenic. According to the literature, the child inherits the tendency to developing atopic disease, individual organ involvement or disease severity. There is evidence that administration of infant food containing potential allergens contributes to increased risk of atopic diseases. A significantly lower incidence of food allergy and atopic dermatitis in infants breast-fed without exposure to cow's milk proteins and other foods rich in allergens during the first months of life was reported. Exposure to various allergens is considered to be the primary cause of the development of asthma in children and young adults.

House dust mites are considered as the most important aeroallergens worldwide. It is interesting to note that there is a strong correlation not only between children's mite exposure and asthma morbidity, but also manifestation of atopic dermatitis. It is probable that cat allergens, cockroaches and molds can increase the likelihood of allergies and asthma, although their role is not as significant as house dust mites [9, 28-30]. Numerous studies have shown that the first months of life (when the process of immune system maturation still takes place) is a period of high sensitivity linked with increased risk of allergic reac- tions from both the gastrointestinal and respiratory tract. What is more, there is probably a link between month of birth and sensitization to pollen. Subjects who were born in the months preceding the pollination season are at twofold increased risk of manifestation of allergy to pollens compared to those born just after its completion. Several epidemiological studies have indicated an increased incidence of childhood asthma, allergic rhinitis and atopic dermatitis in urban areas compared to rural areas (ratio $2: 1$ ). Although it is not fully proven, it is commonly believed that air pollution acts as an adjuvant and promotes development of allergies. Atopic diseases are more common in populations that migrate to industrialized countries and adopt Western style living conditions [9, 31-34].

\section{Allergic diseases - epidemiology}

Globally, two systems of epidemiological studies on allergies and asthma have been conducted recently: the International Study of Asthma and Allergies in Childhood (ISAAC) and the European Community Respiratory Health Survey (ECRHS). The ISAAC study included a survey of children and young people in the age groups 6-7 and 13-14 years and was conducted in 3 phases in 1992-2003 in 56 countries of different regions of the world [5]. The ISAAC study found significant, up to 15 -fold differences between various research centers in the prevalence of asthma (defined as the occurrence of wheezing). In the group of younger children (6-7 years) asthma symptoms were most commonly reported in Costa Rica (37.6\%), Brazil (24.4\%) and New Zealand (22.2\%), and among European countries in the UK (20.9\%). Symptoms of asthma in this age group were detected least frequently in Indonesia (2.8\%) and Albania (5.0\%). In the group of older children (13-14 years), the highest incidence of asthma was observed in Ireland (26.7\%), the UK (24.7\%) and the U.S. (22.3\%), and the lowest in children from Albania (3.4\%), Georgia (5.1\%) and Indonesia $(5.2 \%)[7,35]$.

The ECRHS is a study to assess the prevalence of asthma and allergies in young adults aged 20-44 years, which was carried out in two stages. The first stage of this study, carried out in the early 1990s in 22 countries, mostly European, was a screening study. The second stage, initiated in the late 1990s in 38 centers in Europe, aimed to verify the diagnosis of asthma and allergies. The ECRHS survey covered a total of more than 400000 respondents worldwide $[5,36]$. Also, this study showed significant geographic differences in the incidence of asthma. It was the least often recognized in Greece and Estonia (2\%), and most often in the United Kingdom (8.4\%). Among the reasons for such large geographical differences are mentioned urbanization, the level of industrial development, the associated air pollution and the differences of race, culture, hygiene and lifestyle. It is estimated that in Europe, asthma affects about 30 million people [36]. Both studies show an upward trend in the occurrence of allergic diseases in all European coun- 
tries, but mainly covering regions with rapid economic growth and relatively small, so far, prevalence of allergic diseases. The last 20 years in Poland were a period of significant acceleration of the development of Polish industry and economy, which could also affect the increase in the incidence of allergic diseases as in Western Europe. This fact has led scientists to conduct large-scale, standardized epidemiological studies on this topic.

In 2006-2008, a nationwide survey, Epidemiology of Allergic Diseases in Poland (ECAP), was conducted, based on the complete survey of ECRHS II and ISAAC, translated and validated first through a pilot study and evaluated by experts in the field of asthma, rhinology and dermatology. The study included 22703 respondents in 9 centers and was planned in such a way that the updated epidemiological data were methodologically consistent with pan-European analysis. The data showed a high incidence of asthma and allergies in the Polish population, placing our country within the mean values for Europe [5].

To summarize: the ISAAC study found that in countries where the environment is clean and the food is processed into almost sterile products, allergy occurs much more often than in ethnically comparable but contaminated areas. The study resulted in the refutation of the hypothesis that the explosion of allergies in the 20th century corresponds to the pollution of the natural environment. Moreover, supplementation of food with bacteria present in the environment for thousands of years inhibits unfavorable epidemiological trends. These observations were the basis for the creation of the 'hygiene hypothesis', according to which escape from external stimuli caused by infectious factors caused abnormal development of the immune system, recognizing antigens fully tolerated as foreign [6]. In the occupational environment allergy diagnosis is very difficult, and the detection of a specific allergen is not practicable. In such situations, for many years a diagnostic tool has been the natural exposure test [6].

\section{Allergic diseases - diagnostics}

The mainstay of allergy diagnosis is in vivo and in vitro testing. In vivo testing includes skin prick tests, prickby-prick tests, atopy patch tests and also the skin application food test (SAFT). In vitro testing includes measurement of serum total and antigen-specific lgE using various methods (ELISA, fluoroenzyme immunoassay).

During the last years, also component-resolved diagnostics (CRD) have drawn growing attention as a useful tool in clinical investigation of IgE-mediated allergies. This type of microarray-based testing may be performed using a very small amount of serum sample and it gives a specialist a possibility to determine specific-IgE antibodies against multiple recombinants or purified natural allergen components. Component-resolved diagnostics may be used in the diagnosis of airborne allergy (pollens, animal dander, house dust mites), as well as in allergies to hymenoptera venom or in food allergies to plants (Bet v 1 homologues, lipid transfer proteins, storage proteins).

One of the most significant advantages of CRD is the possibility to evaluate whether sensitization is primary in nature (specific to a particular species) or is associated with cross-reactivity to similar protein structures. This way CRD helps to evaluate the clinical relevance of sensitization and to predict severity of clinical reactions. It may also give a clinician useful information considering the therapeutic effect of specific immunotherapy and may serve as a support in choosing treatment and educating the patient on targeted allergen exposure reduction.

Undoubtedly, all diagnostic tests should be evaluated together with a thorough clinical history, because allergen sensitization may not necessarily be associated with the clinical responsiveness.

\section{References}

1. Respondek W, RISK-Skiba M. Immune system. In: Food allergies. $1^{\text {st }}$ ed. Jarosz M, Dzieniszewski J (ed.). PZWL, Warsaw 2004; 22-32.

2. Thom D. How to deal with food allergies and environmental, nutritional advice and recommendations. KDC, Warsaw 2009; 263-7.

3. Kasznia-Kocot J, Kowalska M, Górny RL, et al. Environmental risk factors for respiratory symptoms and childhood asthma. Ann Agric Environ Med 2010; 17: 221-9.

4. Perez-Badia R, Rapp A, Morale C, et al. Pollen spectrum and risk of pollen allergy in central Spain. Ann Agric Environ Med 2010; 17: 139-51.

5. July A, Komorowski J, Sybilski A, Samoliński B. Epidemiology and pathogenesis. In: Allergy, allergic diseases, asthma. $1^{\text {st }}$ ed. Vol. I. Wave AM (ed.). Practical Medicine, London 2010; 111-30.

6. Hanke W. Epidemiology of allergic diseases of the ground work. In: Allergology professional. Pałczyński C, Kieć-Świerczyńska M, Walusiak J (ed.). Institute of Occupational Medicine prof. J. Nofer, Lodz 2008; 31-61.

7. The International Study of Asthma and Allergies in Childhood (ISAAC) Steering Committee: Worldwide variation in prevalence of symptoms of asthma, allergic rhinoconjunctivitis and eczema atopic: ISAAC. Lancet 1998; 351: 1225-32.

8. Hallas TE, Gislason T, Gislason D. Mite allergy and mite exposure in Iceland. Ann Agric Environ Med 2011; 18: 13-7.

9. Mygind N, Dahl R, Pedersen S, Thestrup-Pedersen K. Allergology. Kruszewski J, Silny W (Polish ed). $1^{\text {st }}$ ed. Urban \& Partner, Wroclaw 1998: 61-109.

10. Asman M, Solarz K, Szilman E, Szilman P. Analysis of expression and amino acid sequence of the allergen Mag 3 in two species of house dust mites-Dermatophagoides farinae and D. pteronyssinus (Acari: Astigmata: Pyroglyphidae). Ann Agric Environ Med 2010; 17: 45-8.

11. Korzon-Burakowska A, Dziemidok P. Diabetic foot - the need for comprehensive multidisciplinary approach. Ann Agric Environ Med 2011; 18: 314-7.

12. Bożek A, Filipowska-Grońska A, Weryńska-Kalemba M, Jarząb J. Nasal nitric oxide measurements in patients with seasonal allergic rhinitis of different age groups. Postep Derm Alergol 2010; 27: 96-100.

13. Samoliński B, Rapiejko P. Evaluation of nasal challenge with different pollen allergens. Postep Derm Alergol 2010; 27: 211-3. 
14. Jahnz-Rozyk K, Targowski T, Owczarek W, et al. Effects of allergic diseases, concomitant with allergic rhinitis, on the clinical efficacy and costs of allergen-specific immunotherapy in Poland. Postep Derm Alergol 2011; 28: 378-81.

15. Pawankar R, Canonica GW, Holgate ST, Lockey RF. Allergy White Paper of the World Allergy Organization 2011-2012. Executive Summary. World Allergy Organization 2011.

16. Majewski S, Cichocki P, Stępnicka-Bindemann M, Górski P. Asthma control, quality of life and successful sputum induction. Arch Med Sci 2011; 7: 84.

17. Radwan ZM, Nasser Yamamah GA, Shaaban HH, et al. Effect of different monotherapies on serum nitric oxide and pulmonary functions in children with mild persistent asthma. Arch Med Sci 2010; 6: 919-25.

18. Kasznia-Kocot J, Kowalska M, Górny RL, et al. Environmental risk factors for respiratory symptoms and childhood asthma. Ann Agric Environ Med 2010; 17: 221-9.

19. Brinchmann BC, Bayat M, Brogger T, et al. A possible role of chitin in the pathogenesis of asthma and allergy. Ann Agric Environ Med 2011; 18: 7-12.

20. Broding HR, Frank P, Hoffmeyer F, Bunger J. Course of occupational asthma depending on the duration of workplace exposure to allergens - a retrospective cohort study in bakers and farmers. Ann Agric Environ Med 2011; 18: 35-40.

21. Kmieć ML, Urysiak-Czubatka I, Broniarczyk-Dyła G. Skin care in children. Postep Derm Alergol 2010; 27: 40-4.

22. Cudowska B, Marcinkiewicz S, Kaczmarski M. Sensitization to cereal allergens in children with atopic dermatitis. Postep Derm Alergol 2011; 28: 181-6.

23. Kurowski M, Majkowska-Wojciechowska B, Wardzyńska A, Kowalski ML. Associations of allergic sensitization and clinical phenotypes with innate immune response genes polymorphisms are modified by house dust mite allergen exposure. Arch Med Sci 2011; 7: 1029-36.

24. Cichocka-Jarosz E, Diwakar L, Brzyski P, et al. Congruence of the current practices in Hymenoptera venom allergic patients in Poland with EAACl guidelines. Arch Med Sci 2011; 7 : 832-9.

25 Karakis GP, Sin B, Tutkak H, et al. Genetic aspect of venom allergy: association with HLA class I and class II antigens. Ann Agric Environ Med 2010; 17: 119-23.

26. Krogulska A, Białek J, Wąsowska-Królikowska K. Bronchial reactivity in school children with food allergy in infancy. Postep Derm Alergol 2011; 28: 268-76.

27. Kaczmarski M, Wasilewska J, Jarocka-Cyrta E, et al. Polish statement on food allergy in children and adolescents. Postep Derm Alergol 2011; 28: 331-67.

28. Żukiewicz-Sobczak W, Cholewa G, Krasowska E, et al. Pathogenic fungi in the work environment of organic and conventional farmers. Postep Derm Alergol 2012; 29: 256-62.

29. Żukiewicz-Sobczak W, Cholewa G. Fungi and substances produced by them as a threat to the health of agricultural workers and animal breeders [Polish]. Institute of Rural Health in Lublin 2011; 96-102.

30. Żukiewicz-Sobczak WA, Sobczak PT, Imbor K, et al. Zagrożenia grzybowe w budynkach i w mieszkaniach - wpływ na organizm człowieka. Fungal hazards in buildings and flats impact on the human organism. MONZ 2012; 18: 141-6.

31. Rodriguez AFM, Palacios I, Molina R. Influence of meteorological parameters in hourly patterns of grass (Poaceae) pollen concentrations. Ann Agric Environ Med 2010; 17: 87-100.

32. Perez-Badia R, Rapp A, Morales C, et al. Pollen spectrum and risk of pollen allergy in central Spain. Ann Agric Environ Med 2010; 17: 139-51.
33. Chowdhury O, Greenough A. Neonatal ventilatory techniques - which are best for infants born at term? Arch Med Sci 2011; 7: 381-7.

34. Szwajkowska-Michalek L, Stuper K, Lakomy P, et al. Contents of microscopic fungi in dusts coming from cereal analysis laboratories. Ann Agric Environ Med 2010; 17: 101-6.

35. Burney P, Chinn S, Jarvis D, et al. Variations in the prevalence of respiratory symptoms, self-reported asthma attacks, and use of asthma medication in the European Community Respiratory Health Survey (ECRHS). Eur Respir J 1996; 9: 687-95.

36. European Allergy White Paper, The UCB Institute of Allergy. Allergic diseases as a public health problem in Europe. UCB Institute of Allergy 1997.

37. Sastre J. Molecular diagnosis in allergy. Clin Exp Allergy 2010; 40: $1442-60$. 